\title{
The Effects of Territorial Depth on the Liveliness of Streets
}

\author{
José Nuno Beirão • Anastasia Koltsova
}

\begin{abstract}
The relation of building entrances with the public space and entrance density is determinant regarding how everyday street life emerges within the street space. The paper proposes a methodology for capturing the liveliness or liveliness potential of streets from their configuration by considering the territorial depth of building entrances. The analytical model is built from a relational graph describing building access seen from the street towards building entrances considering the many levels of territorial depth, or in other words, the many levels between the public core space and the private entrance.
\end{abstract}

Keywords Urban design · Urban configuration · Urban morphology

\section{Introduction}

The character of streets is shaped by many different properties. The street accessibility in the city network is perhaps one of the most searched (and researched) properties that explains how 'successful' that street can be in a particular city. This property is typically assessed with the traditional space syntax methodology (Hillier and Hanson 1984) using the primal graph between streets represented by axial lines, by combining with dual syntax between junctions represented by points (Batty and Michael 2004), or space syntax combined with GIS which allows extending the logic of space syntax analysis beyond the scope of

J. N. Beirão $(\square)$

Faculty of Architecture, University of Lisbon, Gab. 5.1.1, Rua Sá Nogueira,

Pólo Universitário, Alto da Ajuda, 1349-055 Lisbon, Portugal

e-mail: jnb@fa.ulisboa.pt

\section{A. Koltsova}

Wolfgang Pauli Strasse 27, 8093 Zurich, Switzerland

e-mail: koltsova@arch.ethz.ch 
topological analysis by integrating analysis considering distance measures in the axial map. Such is the approach of place syntax methods (Ståhle et al. 2005). All methods capture the probability of a street being used by errant passersby. Although such probability is capable of capturing quite accurately the flows of movement in a city still some local spatial configuration plays a role in determining how much these spaces are able to attract activities and generate the liveliness of a place. Activity considered simply as movement tends to be essentially an expression of traffic intensity rather than people's activity. In any case, none of these methods captures consistently how the rise in traffic intensity cuts a street in two affecting and changing life on both sides of the street.

Other properties still play an important role in determining how 'successful' or how 'lively' a street can be. In addition to the above, Oliveira (2013) proposes other simple properties such as:

- Age of buildings

- Dimensions of street blocks

- Alignment of buildings

- Ratio of building height to street width

- Building use

It is common to find references from several authors (Barton et al. 2003; Moughtin 2003) arguing that the urban environment is also shaped by architectural characteristics, such as building typology, the building position within the plot, ${ }^{1}$ façade design, etc. Complementary to these properties we may add other properties more related with the architectural features of the built environment rather than just the usual (more abstract) urban features. The main argument in this context is that the position of building entrances matter. The topic is not new, it actually plays an important role in the foundation of space syntax theory where such features may be represented through the use of an interface map, but still lacks more in depth insight. Habraken (2000) points out how different configuration of entrances in architecture or in the aggregation of architectural types can play a role in determining different kinds of relationships between streets and private spaces (housing or other) by increasing the territorial depth between street (public) and private space. Habraken shows several built devices designed in different cultures to increase the territorial depth between streets and houses. Among such devices Habraken shows front gardens in sub-urban and urban contexts, stoops, raised balconies (private or public) and arcades. Most of these devices in traditional cultures (the ones in Habraken's examples) create a kind of reserved distance from what otherwise would be a direct connection between private and public spaces. Such reserved distance can be seen as positive because they preserve a level of privacy which is in accordance with the local culture. However, as pointed by Hillier and Hanson, too much territorial depth can segregate the living spaces from the public spaces in a way that affects negatively the street space, namely by removing the possibility of commercial

\footnotetext{
1 This property influences the 'Alignment of buildings' but relates essentially with the way the building is implanted in the plot and how many steps in privacy level one needs to take from (public) street space to (private) building space.
} 
activity facing the streets (shops) or by hiding the street from the inhabitants view and therefore affecting negatively the natural street surveillance as already stressed by Jane Jacobs (1961).

In many countries, based on the excuse of raising security, the resource to devices increasing territorial depth has been used to extreme levels, creating street environments that are hostile to common street life. Such devices are used profusely especially in developing countries where the higher classes demand the use of structures that separate them physically from streets. The resource to large scale gated communities has become quite common in these countries and practiced abundantly without any thought on the consequences. It is astounding the change that we see, for instance, in the Brazilian cities comparing today's situation with their structure in the 50s where street life was obviously much praised. Today in the new areas mostly walls, tall fences and many times barbed wire face the streets, creating very unpleasant urban environments.

It would be useful for planning purposes to measure objectively how specific street configurations affect security and in particular to measure the impact of these devices increasing territorial depth.

This study intends to set an objective way of measuring the configurational properties of streets that affect their overall 'liveliness' or 'success' and presents a method and a set of tools for such purpose.

\section{Approach (Methodology)}

The ultimate goal in this study is to define a way of objectively measuring the relation between street life and how streets and private spaces connect in order to better understand how to design and plan the public space. There will be a focus on the role of territorial depth and on the density of entrances in street façades. These properties as well as a number of other factors that will be described later in the text will be simultaneously considered for the analysis of a street permeability. The ultimate goal of the paper is to reveal the possible correlation between the street permeability and street liveliness.

In the space syntax theory, Hillier (1984) describe settlements as groupings of primary cells or buildings designated by $X$ which are distributed within an outside carrier space $Y$ considered not to be part of the settlement. Gardens, courtyards and property boundaries are considered to be secondary boundaries and represented as $x$. Any arrangement of $X$ or $x$ is surrounded by different configurations of open space that we know as streets or more generically as open spaces. These open spaces are represented as $y$. A settlement becomes therefore an arrangement of $X-x-y-Y$ where $X$ represents the most local and $Y$ the most global representation of the settlement. We could also say that $X-x$ represents the private space or the space of the inhabitants while $Y-y$ represents the public space or, as the authors say, 'the domain of strangers'.

Considering the cells $(X)$ to be the most deep spaces in a settlement and a particular street to be the carrier $Y$, some aspects of the street life may be understood in terms of the mean depth of $X$ in relation to $Y$. Depth in terms of this relation may 
be measured by counting the steps of territorial depth of sequential permeable spaces starting from $Y$ towards any cell $X$.

Although inspired by the principles of space syntax we want to read streets as single entities rather than sequential convex spaces which are often the case in streets having geometric variation along their continuity or as axial lines. Also, in our approach streets are considered individually and not as streets in a network representing an entire settlement or a large part of one. There is a substantial difference in this situation. On one hand, the topological role of the street in the settlement is lost (or considered separately at another level of detail), but on the other hand, the details of street configuration become important and play a role on the way streets behave. Let us pinpoint a few relevant aspects that shall be taken in consideration:

1. Street width seen in terms of the distance between the two sides of the street.

In most narrow local streets people can use the two sides of streets without much thought on which side of the street offers more activity for they can easily cross from one side to the other. However, when streets become very large and include many traffic lanes, roads in the middle of streets become a barrier that creates or intensifies the differences between the two sides of streets. In extreme situations the two sides can have entirely different structures and entirely different street life. Therefore, there should be a way of measuring the permeability between the two sides of the street and including such property in the overall evaluation of street behavior.

2. The two sides of the streets can have totally different behaviors.

The previous point highlights the fact that the two sides of the streets may have totally different behaviors and therefore the street sides have to be considered separately. We could say that the overall street life will correspond to some relation between what happens on each side of the street and the permeability between the two sides.

\section{Types of building entrances.}

Cities present many different types of building entrances. The same can be said about cultures. Particular types may be particularly appreciated by a specific culture and almost inexistent in another. Habraken (2000) clearly points this aspect and shows that such types sometimes even add some levels of territorial depth between the public space (street) and the private space (the cell). An extreme example of this is the entrances to houses in the Arabic medinas where the progressive narrowing of a cul-de-sac ${ }^{2}$ is intensified by successive turns increasing territorial depth. Territorial depth is built within the scope of the $y$ space, that is, within the scope of the public space.

On a different level, we may also distinguish two types of entrances in their relation to the $x$ space: (1) direct entrance to private cells; and (2) entrances to a distribution space which although private are still shared space and simply

\footnotetext{
${ }^{2}$ It is called Derb.
} 
constitute an additional step towards the private cell. Territorial depth is built within the scope of the $x$ space, that is, within the private space.

4. Types of intermediate territorial spaces.

As a consequence of what was described in the previous point we may identify different types of intermediate spaces between $Y$ and $X$, some within the public domain and others within the private domain. Intermediate $y$ spaces (public domain) will mainly be outside spaces while intermediate $x$ spaces (private domain) may be either outside or interior spaces. As an example of an intermediate $y$ space we may point an inner courtyard directly accessible from the street which gives access to entrances. As an outside $x$ space we may consider a private front garden as an example. And as an example of an interior $x$ intermediate space we can consider space such as a distribution hall or gallery.

\section{Cul-de-sac situations.}

When a cul-de-sac is accessed from a street A, we can say that the access to this cul-de-sac is dependent on street A and therefore street A will definitely be affected by what happens in the cul-de-sac. In other words, entrances in the cul-de-sac can only be accessible from street A. Therefore, when evaluating the behavior of street A one should consider the accessibility to entrances in all spaces which are only accessible from street A, namely in such cul-de-sac situations.

6. The physical distance from other streets.

Conversely, when the physical distance of an entrance from a street A being studied is longer than the distance to another street (say, a back street), one should not count it as contributing to the street life of street A. However, this point should be supported by local observation of such evidence as it is not always necessarily true. Furthermore, for strangers many times the address will be the main reference and they will probably access that entrance coming from the main street only to discover that an alternative access will leave them closer to the entrance.

Considering the above six points, we can easily understand that the representation of the models to be used for street analysis may need to be prepared individually taking the above criteria in consideration.

In order to measure the properties of streets that are dependent on permeability between $Y$ and $X$, and seen in detail considering all levels of territorial transition in $y$ and $x$ spaces, we need to first establish a representation of streets in terms of their $Y-y-x-X$ spaces as well as their permeability relations. A street will therefore be seen as a single system accessible from the carrier $Y$. Any street giving access to a street A will therefore be considered as part of the carrier dividing the street into a set of sequential segments (all of depth one) from which more detailed representations of the space towards $X$ will be defined following the above criteria.

Getting back to the above six points, we should consider how they may be incorporated in our representation model in a way that is objective, widely applicable and unambiguous. First of all, we shall deal with the ambiguity of convex spaces representation by concentrating on the representation of clearly unified spaces representing autonomous territorial spaces. The convex space becomes the 
identification of perceptible autonomous places with no separation elements such as fences and gates. Convexity is still the main concept but spaces are further subdivided by other separation elements. We shall call these territorial spaces or steps. Second, to define streets consistently we will follow the criteria developed in the next subsections.

Street Width (1) and the Two Sides of Streets (2)

People cross local streets almost at any spot if local traffic is slow and safe. Some streets are even used by children to play ball. If traffic intensity grows just a little bit streets start to have the need of having specifically located zebras for street crossing. In many cases, such streets are still perceived by many people to be reasonably safe for crossing at any point especially if such street has just one or two traffic lanes. However, when streets become larger, including three or more traffic lanes people start perceiving such streets as dangerous for crossing at any spot rather than zebras and preferably with traffic lights. When the streets become very large including many traffic lanes we can see more devices separating each side of the street, for instance, central separations between traffic directions with or without landscape arrangements. In some cases, such devices constitute a physical barrier separating in a definitive manner the two sides of the street. The simpler streets may be considered a single social space while the main arterial and collector streets may be considered to have two separate although maybe complementary social spaces. In order to deal with this feature we should define the analytical models of streets by distinguishing these two basic types of situations. The first case (that we will call traversable streets) considers a simple model where the street is the lowest level from the carrier $Y$ and represented by a line with a $j$ number of junctions connecting to the carrier and an $l$ number of links to the first territorial step towards $X$ which in the lowest depth will be a direct entrance from the street. In this case, the street width $w$ will usually be reasonably small and it will be considered totally permeable between the two sides all along its length.

The second case (that we will call dual street) considers the two sides of the street separately. Each side of the street has a $j$ number of junctions with the carrier, a $z$ number of crosswalks linking each side of the street (street crossings of any kind) and an $l$ number of links to the first territorial step towards $X$. The street width $w$ will usually have higher values. We can also say that the number of traffic lanes is obviously related with this segregation of the sides of streets between each other. Note that in the second case the street segments are represented separately on the two sides of the street. The junctions $j$ divide the street or street sides in a number of street segments $s$.

In these situations the permeability between the two sides of the street or crosspermeability $(C P)$ could be measured by considering the number of crosswalks in the street. In this situation, crosswalks count as links that rise the cross-permeability $C P$ from 0 (for no way to cross) to 1 which would be the hypothetical street that is entirely composed of crosswalks, in other words, the equivalent to a traversable street. Therefore, considering that a street crossing area will take the average size of $10 \mathrm{~m}$ in large streets from its total length we may say that the permeable length of 
that street will be ten times the value of $z$. And the cross-permeability or permeability between the two sides of the street may be calculated as Crosspermeability $(C P)$

$$
C P=\frac{10 * z}{\left(\sum_{i=1}^{n} l s_{i}\right) / 2}
$$

where $l s$ is the length of a street segment. The equation considers the total length divided by two to eliminate the street length duplication in the dual street models. This value of cross-permeability can be used to correlate the liveliness on the two sides of the street which can in many cases be quite different.

\section{Types of Building Entrances (3) and Types of Intermediate Territorial Spaces (4)}

The analytical model will need to count the territorial steps towards the private cell (the $X$ space). We will have steps in two different kinds of space: steps within the public space $(y)$ and steps within private space $(x)$. In the public space we will consider all the spaces representing a step further towards a private entrance. The sidewalk represents the most public space within the public domain. Any recession from the sidewalk will constitute a second step, e.g., a retreated public garden, a courtyard, an arcade with shops, an elevated gallery, a plateau towards an entrance, combinations of these, and so on. Figure 1 shows a set of examples of these spaces.

In many situations, buildings standing on a plateau will have entrances at two different levels: directly from the street and from the plateau. In the latter situation, the access to the plateau might be done through a public staircase or by a back street on a different level. In these situations the staircase should be considered as one territorial step and each isolated space in the plateau as another territorial step. These are all territorial steps defined within publicly accessible open space, i.e., within the $y$ space. In the private space $(x)$ we shall consider in our analytical model just the outside spaces. For instance, in gated communities people will commonly take several territorial steps before they reach a cell $X$. Just as an example, such spaces may be an entrance to gated area, a street towards a common parking lot, a distribution garden giving access to different isolated buildings. Although, we know that in such buildings we may still find several levels of territorial depth depending on how individual cells are distributed inside the collective building (e.g., entrance halls to apartments, distribution from long galleries), the detail of our model ends at this level. However, this decision liberates us from the need of collecting detailed information on building typology and does not change much the information on how buildings' configurational arrangements influence life in a street.

\section{Cul-de-sac Situations (5)}

If a street A gives access to several highly populated cul-de-sacs, this street will definitely be much more active than if we do not have such access. The important detail to consider here is that a cul-de-sac will not be accessible from any other 
street and therefore its existence affects in a determinant way the traffic and activity along that street A. Therefore, it seems reasonable to consider a cul-de-sac just as another territorial step (or sequence of territorial steps) towards entrances. This topic will be further developed when analyzing the case of Guilhermina Suggia Street in Lisbon (Fig. 2). At this point, the reader should be aware that a cul-de-sac is not a connection to the carrier and therefore does not affect the number of street segments of this street. Considering the case of Guilhermina Suggia Street, we can see that this street connects the carrier on its two extremes and, although connecting three cul-de-sacs, it should be represented by a single segment to which all other territorial levels or direct entrances connect. To distinguish the two representations we shall call street segments to all subdivisions in a street including cul-de-sacs and street sections to the resulting segments when excluding cul-de-sacs. Street graphs are drawn from the street section representation. When calculating the average distance between entrances in that street the length of the cul-de-sac segments should be added to the total length of street segments (or street sections).

\section{The Physical Distance from Other Streets (6)}

Some street configurations segregate so much some entrances relatively to a main street that although many times officially having an address from the main street they are physically closer to a back street or a secondary street. See the example of Av. E.U.A. (Fig. 11). In such situations, inhabitants tend to access their houses from the secondary street avoiding the use of the main street. Although in many cases the main street still plays the role of the collector street giving access or participating in giving access to the

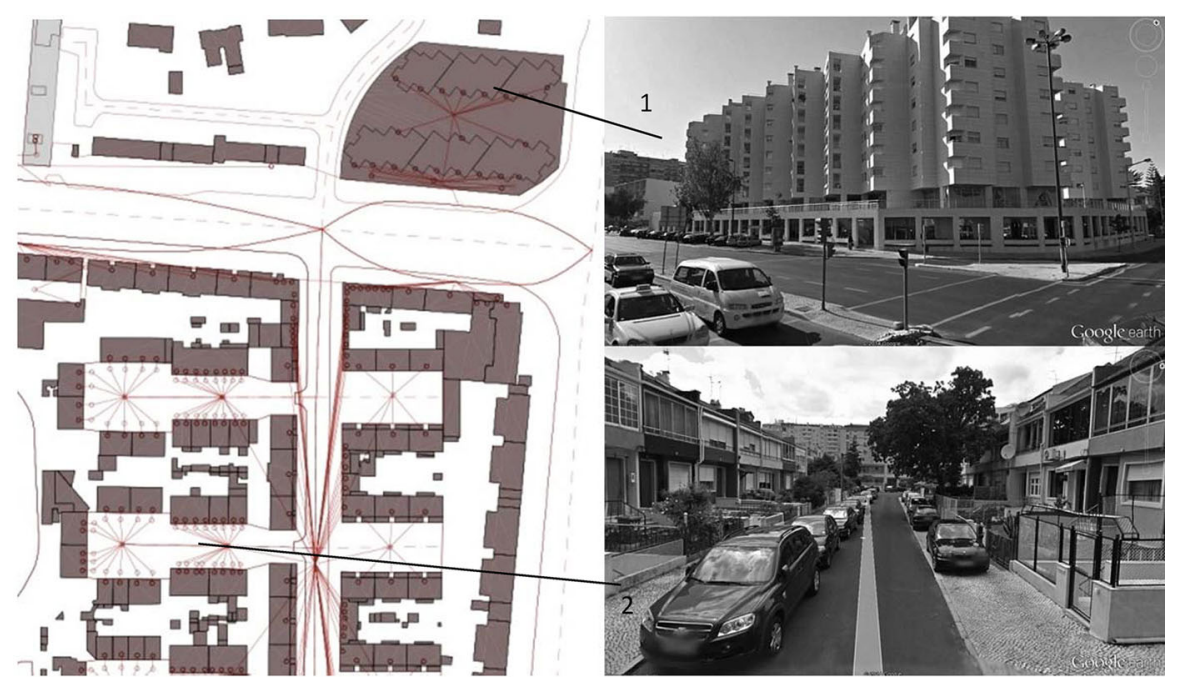

Fig. 11 Av.EUA: detail of building standing on a plateau; 2 row houses at R. Guilhermina Suggia. Some of the commercial spaces in the plateau were never used. The entrances to the distribution hall of the apartment buildings face the elevated backyard in the plateau. The long thin building in the upper left corner has all entrances facing the back street 


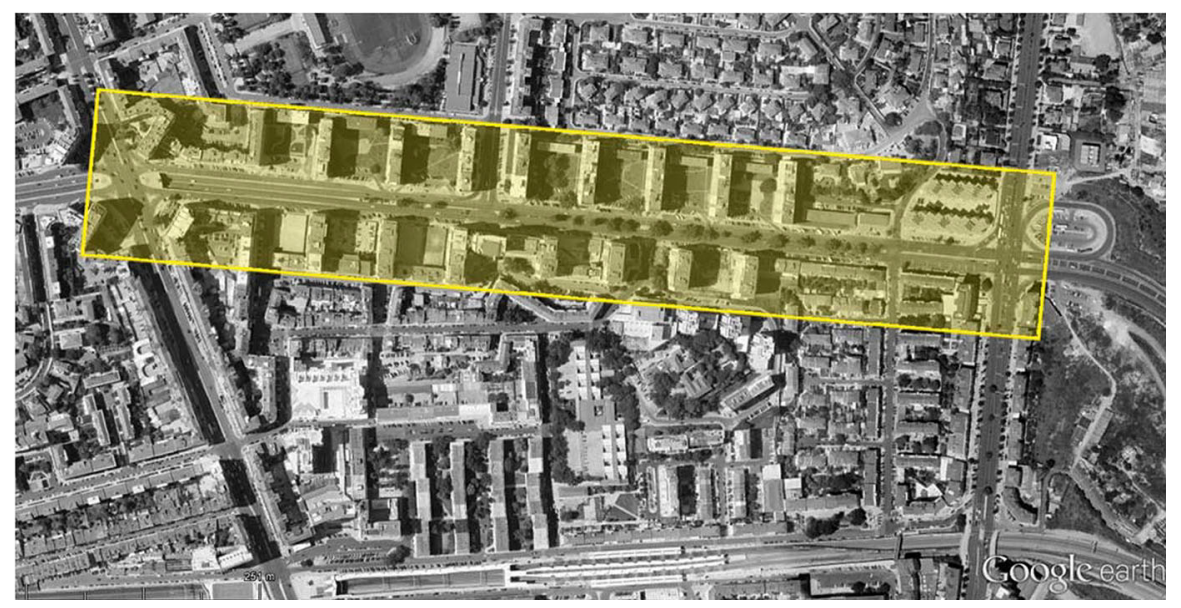

Fig. 2 Lisbon case study-Av.EUA

secondary street, still it may not succeed in bringing life to the main street. Such situations may be seen twofold: (1) either they are not considered in the analytical model of the main street or (2) they are but the model should clearly describe the obvious high level of territorial depth present in such a situation. The decision whether to choose the former or the latter form should be a subject of interpretation based on observing if the street is really used or not in the ambiguous manner.

Summarizing, the analytical model of a street (which we will call the permeability map) will be represented by the collection of sequential street segments connecting the carrier $Y$ and their links to all the sequential territorial steps (shortest topological path) until they reach an entrance to a cell $(X)$. The result is a detailed interface map $^{3}$ of the street which can also be represented in the form of a justified graph. By following space syntax theory we can extract values for mean depth and relative asymmetry from the graph. We can also calculate other additional properties: total number of entrances; total number of intermediate steps, total depth, number of entrances at the first depth level or facing the street; number of links at first depth level; maximum depth; average number of entrances per $100 \mathrm{~m}$; average distance between entrances. From this point on, we can discuss the properties that can be taken from this analytical model and their meaning regarding the behavior of the streets. The model calculates also measures for the average length of street segments and the average size of islands facing the street. Following the conventions of (Berghauser Pont and Haupt 2010) we call 'island' any parcel of urban territory surrounded by streets. This nomenclature disambiguates uncommon very large city blocks like some of the examples shown in this paper.

\footnotetext{
3 The permeability map can be seen as a detailed interface map for a single street using territorial steps instead of convex spaces. The term interface map follows Hillier and Hanson (1984) convention.
} 


\section{The Properties of Street Permeability}

The street models for analysis were built on a CAD platform with the aid of a visual programming interface (VPI). In this case, the CAD environment was Rhinoceros and the VPI was Grasshopper. This environment profits from the possibility of using design patterns (or modular codes) for systematically and very easily build the analytical models.

Formally speaking any model built for the analysis of a street's $Y-X$ permeability is represented by a set of representations that we shall call the street model (STR). Any street model is an arrangement of representations of different kinds of objects belonging to different sets of homologous elements. These sets are: entrances (E); links or connections (C); territorial steps (T); buildings (B); islands (I); axes (A); and street segments (S). Elements of $\mathrm{E}$ and $\mathrm{T}$ are represented by points (or large dots for visualization); elements of $\mathrm{C}, \mathrm{A}$ and $\mathrm{S}$ are represented by lines; and elements of $\mathrm{B}$ and I are represented by polygons. The territorial steps are therefore represented by their center points rather than their actual shapes. The street model for a street A is therefore an arrangement of subsets of these representations:

$$
\mathrm{STR}_{A}=\left\{\mathrm{E}_{a}, \mathrm{C}_{a}, \mathrm{~T}_{a}, \mathrm{~B}_{a}, \mathrm{I}_{a}, \mathrm{~A}_{a}, \mathrm{~S}_{a}\right\}
$$

A street model takes the E, B, I and A representations from a geographic information system or simply from a geometric model organized in a similar fashion. In general these representations are existing data. Street segments $\mathrm{S}$ are drawn according to the previously referred criteria even though it may use elements from set A which are copied to set $\mathrm{S}$. The territorial steps $\mathrm{T}$ are added as points by the user allowing for a mindful representation of the intermediate steps between street segments and entrances. This representation implies a classification of all the point representations with a depth value which will become a property of those points. Links in set $\mathrm{C}$ are generated automatically by linking territorial steps of depth $d$ to entrances of depth $d+1$. The working platform uses a small set of design patterns to build the analytical models. All streets are modeled using five patterns, two other are used for visualization, one for counting depth and links, and finally another one to perform the calculations.

The analytical models measure a set of properties of streets focusing on the concept of depth. Depth in our street models express the intensity of the connectivity of the street seen from the first $y$ step towards the private cells representing the $y$ $x$ permeability of streets. Below we show a list of properties being calculated by the models for a street A and explain their meaning in terms of our analytical goals.

\section{The Case Studies}

A set of case studies from different cities in different countries was chosen for analysis. The main idea is to collect a reasonable number of different cases to gather enough diversity for a comparative analysis of results. The selected cities were: Lisbon, Moscow and Zurich. These cities were chosen for being well known to the authors and hence allowing the accurate representation of the analytical models. 


\section{Lisbon}

In Lisbon we chose different streets taken from a modern neighborhood (Alvalade). This plan implementation started in the 50s and was finished in the 60s. The first plan was developed still in the 40s. It was a large plan composed of one main central avenue (Av Roma) which is the main composition axis oriented in a south-north direction and crossed by four other structural or arterial avenues. This fundamental grid subdivides the whole plan in several smaller areas which are perceived as smaller neighborhoods inside the larger one. A train line bisects two of the areas into four smaller ones. Each of these smaller neighborhoods contains some facilities and public buildings of some kind-churches, primary schools, kindergartens, secondary schools, swimming pool, local library, a psychiatric hospital, a fire station, the national civil engineering lab and other less relevant facilities. The neighborhood is in general perceived as a nice neighborhood and is well connected with the city center both in terms of street connectivity and public transportation (subway, bus and train). It is also close to the airport. In fact, the eastern boundary of the neighborhood is the main access axis connecting the city center and the airport. As a whole, Alvalade is perceived as one of the best modern areas in Lisbon and is one of the most expensive in terms of land value.

From this neighborhood we chose four streets: two of the four east-west axes crossing Av Roma; and two local streets. In both cases we selected streets that could be perceived as contrasting examples. The two east-west axes are Av Estados Unidos da América (Av EUA: Figs. 3, 11) and Av da Igreja (Figs. 4, 5). Av EUA was planned to be part of the first ring road of the city but the ring ended abruptly at the east end of this avenue which was only continued later by the end of the 90s. As such Av EUA only developed its ring function in the 2000s. The avenue has a typical modernist structure being composed essentially of tall buildings

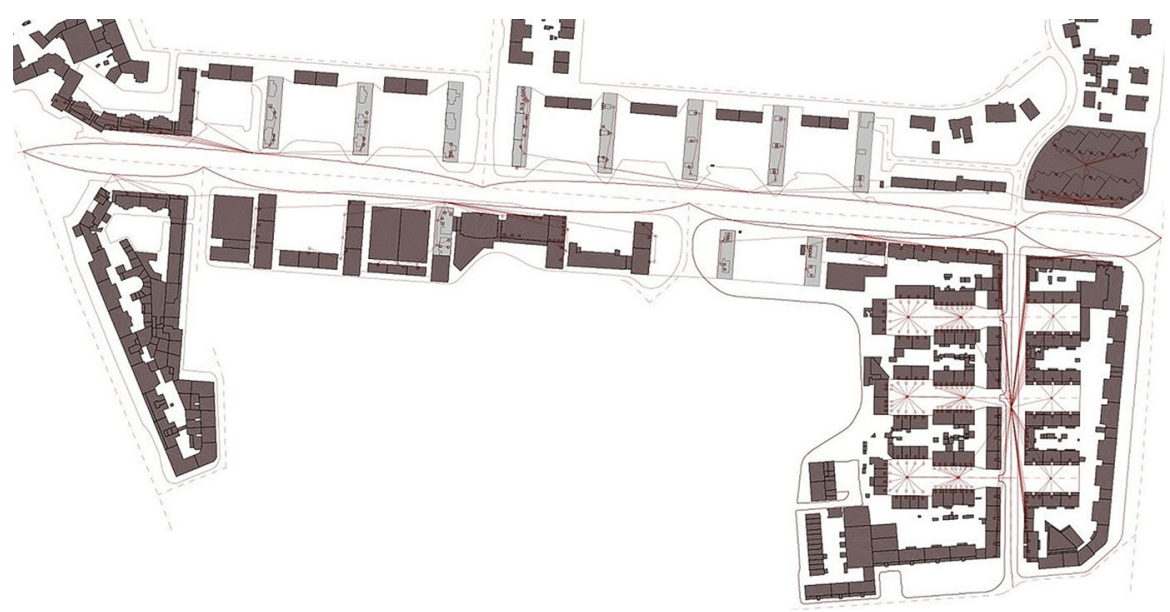

Fig. 3 Av.EUA and R Guilhermina Suggia: models and the generated graphs. Guilhermina Suggia connects Av.EUA at the east end. However, life at GS contrasts intensely with the activity at Av.EUA. The higher activity at GS may be explained by the density of entrances along this street 


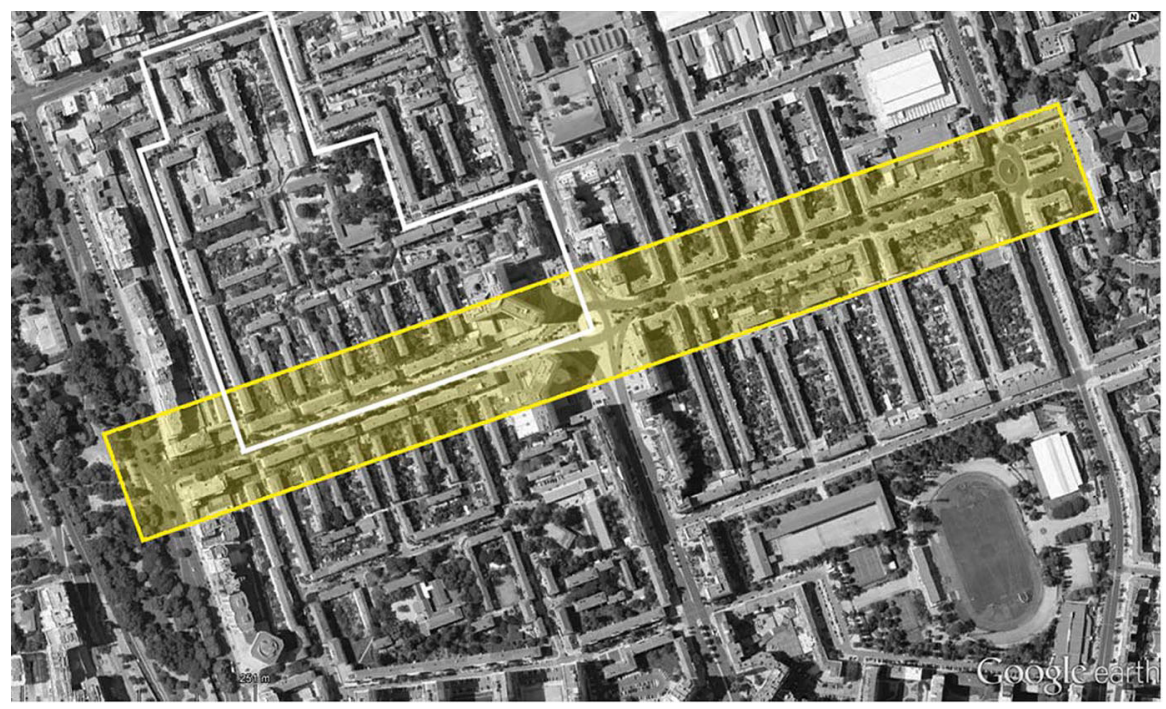

Fig. 4 Av da Igreja. The area surrounded by the white line shows the large island facing this street and the R Afonso Lopes Vieira. It is also the largest island in the neighborhood

perpendicular to the street with green interstitial garden spaces. Although full of green spaces, they are not used as intensively as expected. In fact, in the whole Alvalade neighborhood this avenue was the only one ever perceived as not being safe. However, such perception has changed a bit along the many decades since the avenue was built. Av da Igreja is the absolute opposite. This avenue was planned as a large local street; as the main axis of a small neighborhood and is perceived as such. Even the name (Av da Igreja means literally 'the avenue of the church') stresses the idea of community headed by the church placed at the top of a square heading the east end of the avenue. The church is seen from any point in the avenue.

The two avenues are cut in two by Av Roma. While Av EUA shows similar kind of activities and similar life on both sides, Av da Igreja has absolutely different environments on each side: the west side is quiet and mainly residential (and sometimes seen as less secure) while the east side is always bursting with activity, fraught with commerce and is considered to be one of the most pleasant areas in the neighborhood. Due to the extreme changes in environment along Av da Igreja, the analytical model for this street was divided in four sub-models: the west side; the east side; Praça de Alvalade which is the central square at the junction with Av. Roma; and the church square at the east top (Figs. 4, 5).

The two local streets have a peripheral location in Alvalade. R Guilhermina Suggia (R.GS: Fig. 6) is a very lively example even though reasonably isolated from the livelier areas of the neighborhood. Although essentially residential, R.GS contains a lot of commercial activity including local commerce such as a grocery store, barber shop, cafés, butcher, restaurants and others, most of them along the same side of the street. Three nice cul-de-sacs connect the street at the west side and 


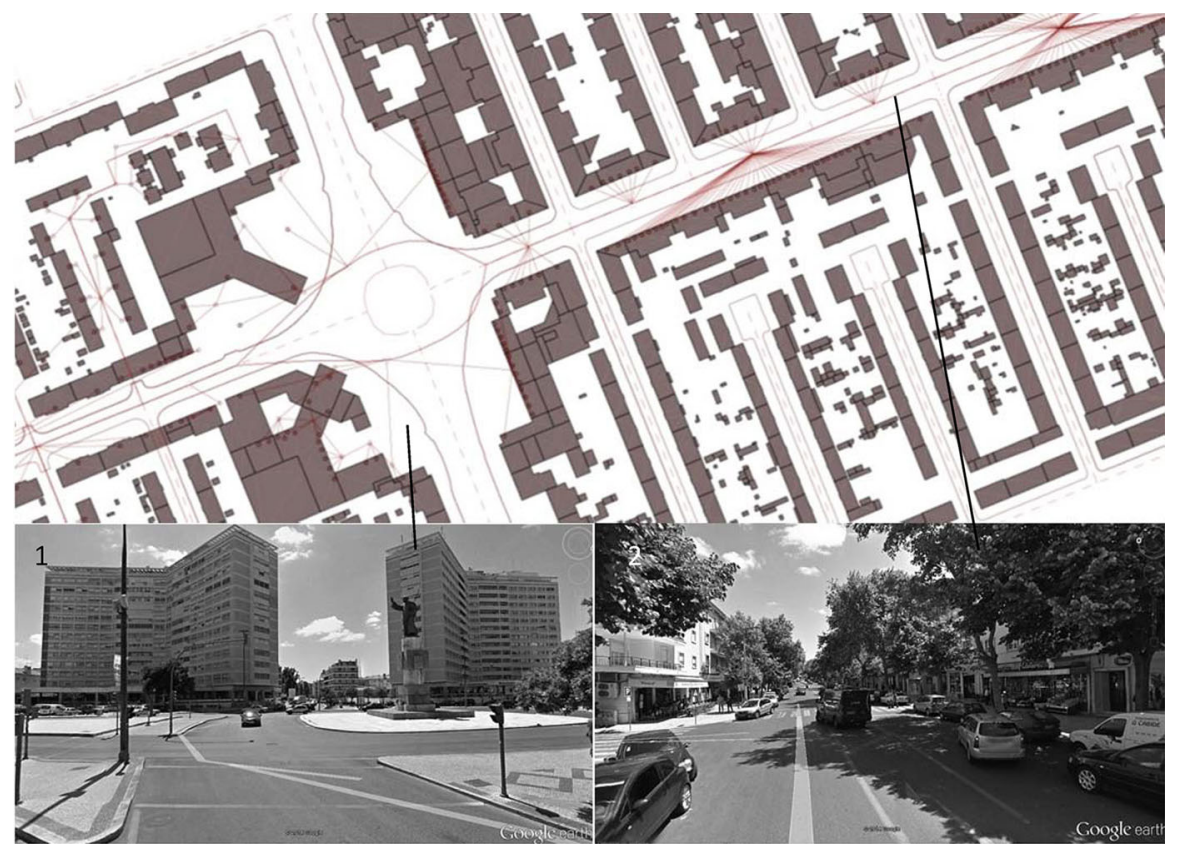

Fig. 5 Av da Igreja. 1 Central square with tall modernist buildings standing on a commercial podium. 2 On the east side all entrances are accessible directly from the street

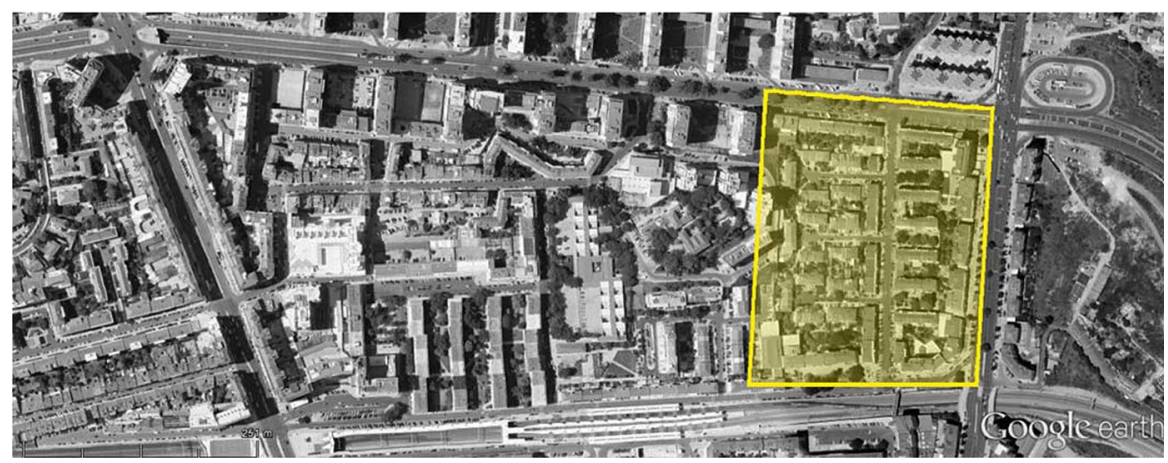

Fig. 6 Lisbon case study-R. Guilhermina Suggia

are all composed of row houses with a small front yard. These cul-de-sac areas are perceived as very pleasant residential areas in spite of the parking problems (Fig. 1).

R Afonso Lopes Vieira (R.ALV: Fig. 7) is another peripheral street within an area fundamentally planned to be residential. R.ALV crosses Av da Igreja at its western end. This street is quite peculiar in the sense that the street toponymy does not correspond to either street continuity or street hierarchical structure. Being a secondary street with respect to Av da Igreja one could expect to find different 


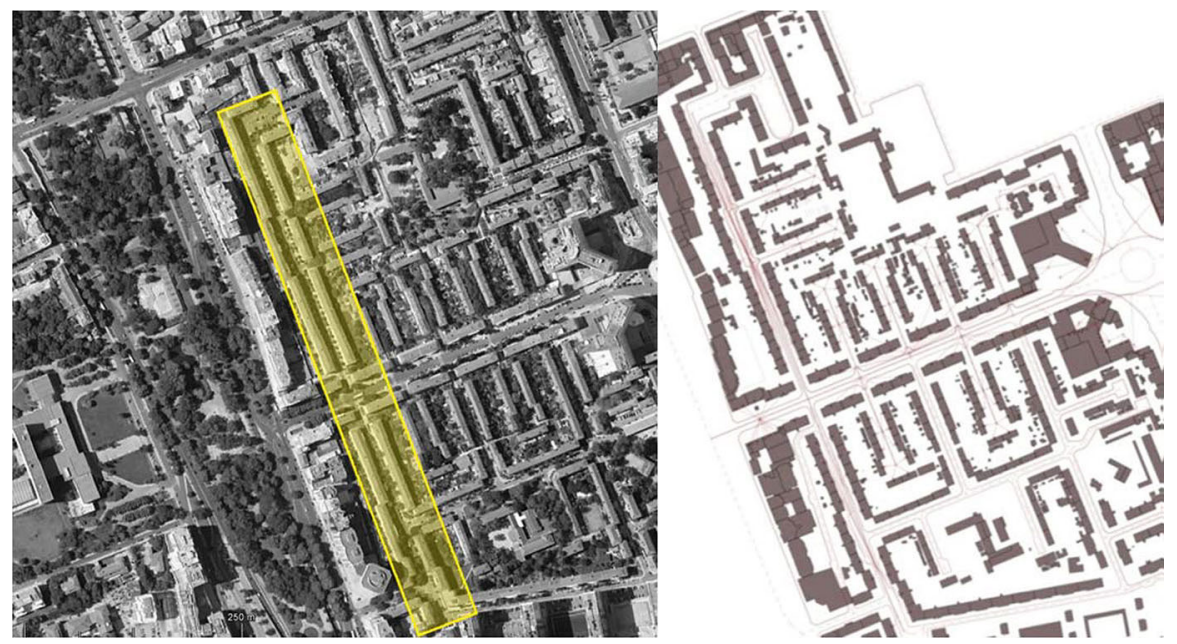

Fig. 7 Lisbon case study-R. Afonso Lopes Vieira (R.ALV)

names on each side of it, or, accepting that continuity could be the criterion to choose the name, we could also expect that the street would keep its name in spite of the turns as long as it would keep its continuity, but in this case the name is kept only as it stays in the same straight line. The ends of the street are simply turns towards other very similar streets. Another peculiarity is that, although being internal to a local residential area, it can be used as a traffic detour at rush hours by those who are familiar with it and profit from such detour. Because it is a one-way street (with a single traffic lane) it can only be used as such in one direction. Finally, this street gives access to a set of cul-de-sac areas within the neighborhood reinforcing its use. It should be stressed that this area contains the largest island in the whole Alvalade plan-it is the only island wide enough to confront three of the main arterial avenues of the plan and has the total area of 105,783,9 $\mathrm{m}^{2}$ (see Fig. 4).

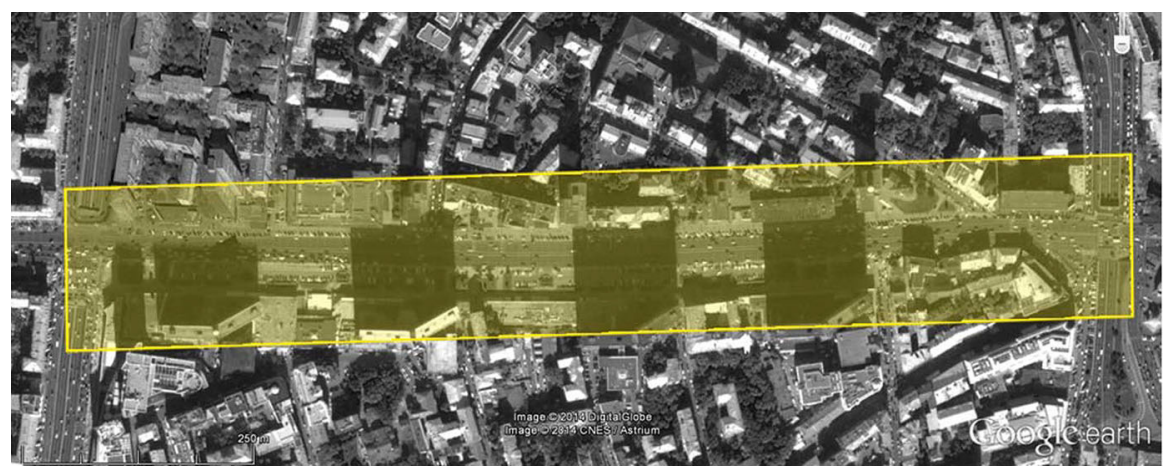

Fig. 8 Moscow case study I. New Arbat Avenue 


\section{Moscow}

The case studies in Moscow, Russia represents the two extremes: (1) the avenue with total of six lanes which mostly accommodates office/public functions and retail/entertainment, where each side has to be analyzed separately and; (2) the local narrow street (mostly housing with small retail stores at the ground level) of two car lanes that can be crossed at any point and should be considered as one space.

The first case study, the New Arbat avenue (Figs. 8, 9), presents an interesting case where two sides of the street have different morphology, thus, forming open spaces with distinctive qualities. On one side the pedestrian space represents a wide promenade with sitting spots and green loans. The multiplicity of shopping and entertainment possibilities (casinos and bars) creates a vibrant atmosphere. The other side of the avenue is narrow with some shopping and dining facilities and implies more directional movement. There are no spaces for lingering or sitting as the close proximity to the road makes it impossible due to the car noise. Historically, this avenue has been constructed as a major link between the president's residence and Kremlin which is the governmental center in Moscow.

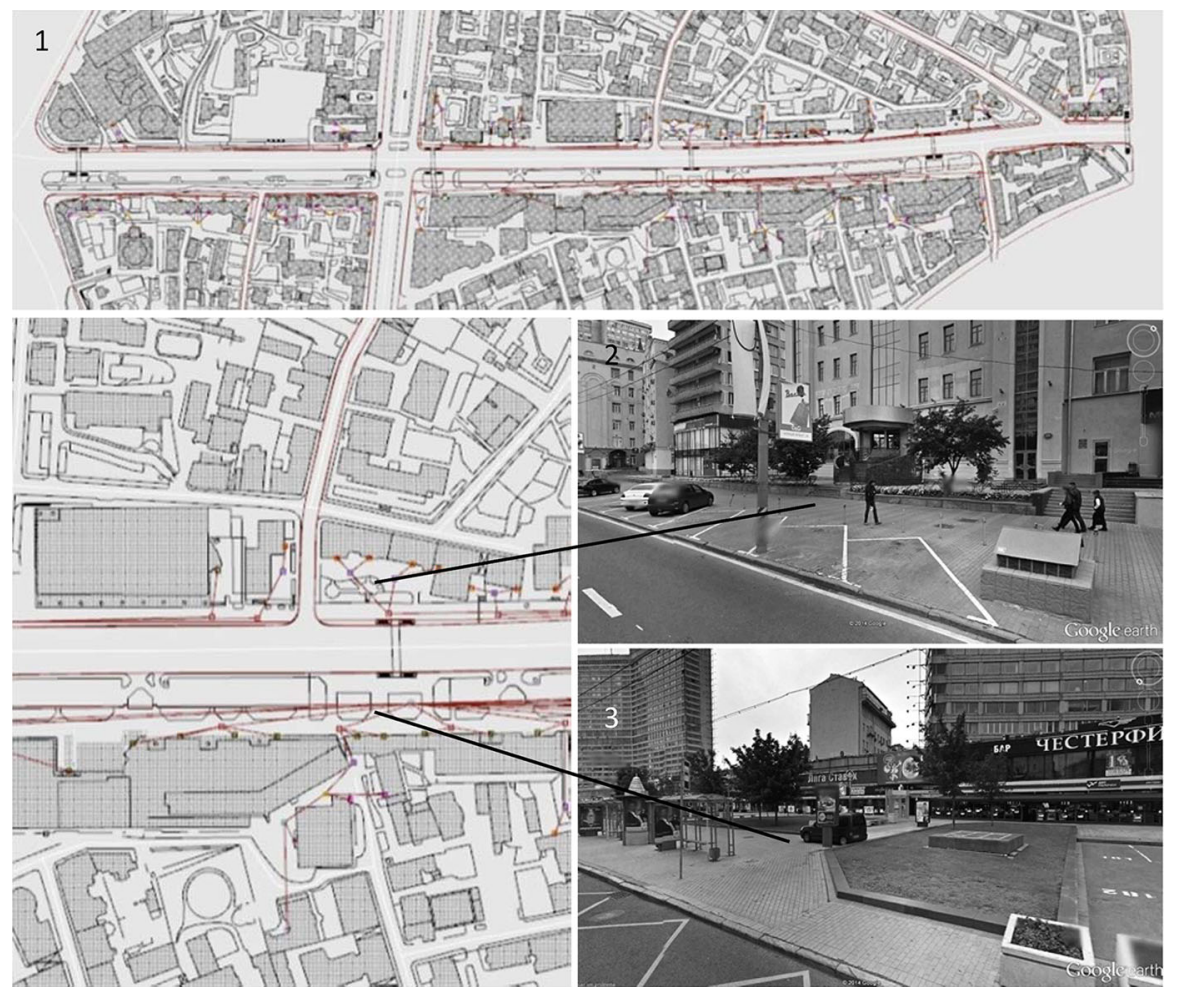

Fig. 9 Av New Arbat (1) models and the generated graphs. Some of the deeper entrances are shown in the zoomed area (2) street view on one side of the avenue with lesser pedestrian amenities (3) another side of the avenue with wider pedestrian walks and open cafes 
One may observe that it is a rare case in Moscow when residential building entrances go directly into main street. Typically, it is possible to enter the building through the courtyard located at the backside of the building (currently most of them are gated), while front side of the building, facing the main street, is populated with entrances to small retail stores. The second case study, Donskaya street (Figs. 10, 11), presents a typical example of such kind of street.

The planning regulations in Moscow (especially in residential areas) imply that entrances to private spaces $(X)$ should be separated by an open space (loan/ playground/garden) from the main street $(Y)$. Below we analyzed one example of such public-private space arrangement at Donskaya street and classified it according to $Y-y-x-X$ principle proposed in the first part of the paper (Fig. 12).

\section{Zurich}

On the contrary, the situations in which building entrances run directly into public space of a street is a common case in Zurich, Switzerland. We will be looking at the examples in Zurich center as well as closer neighborhoods. Overall, typology of the development in Zurich is similar throughout the city center. Those are mostly fivestorey buildings: either multiple apartment raw houses or perimeter blocks that are typically accessed from the street. There is no gatedness that would characterize the more wealthy areas of the city as compared to our other case studies in Lisbon or Moscow. The level of the area very much depends on the land value which is mostly dictated by the proximity to the Zurich lake. The lake shores are called "Golden" due to the high property prices. However, in terms of arrangement of built and open spaces "poor" and "reach" areas have much in common. The first case study is Langstrasse (Figs. 13, 14). This street offers large variety of entertainments: from night clubs and bars to shopping and dining. This street has a very intense live

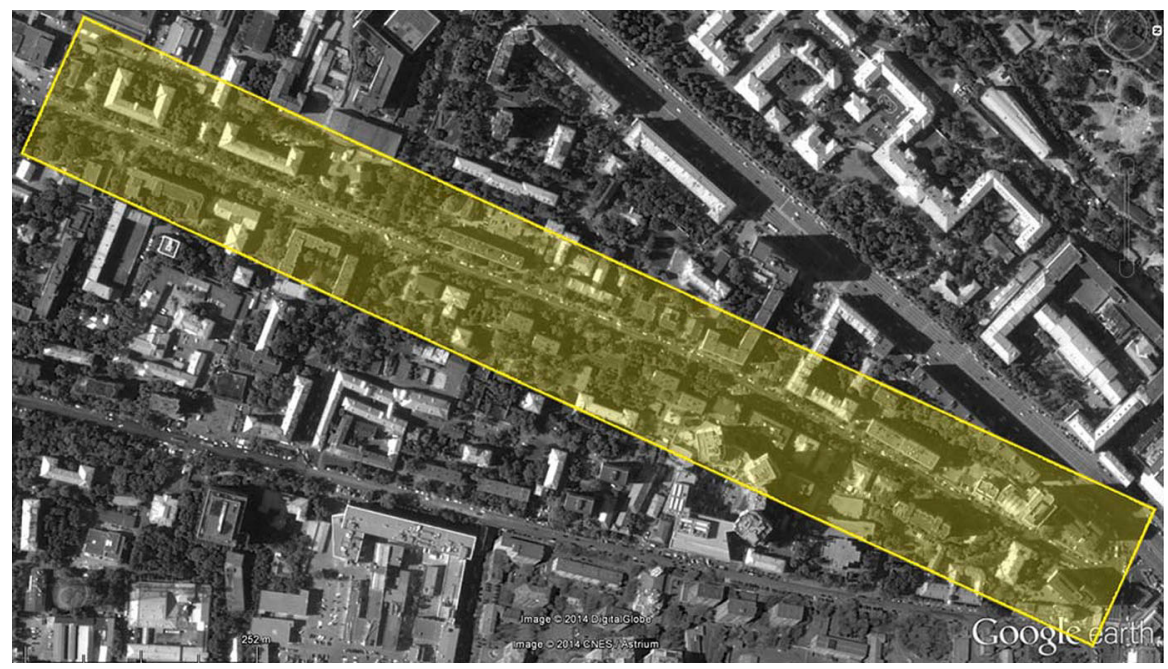

Fig. 10 Moscow case study II. Donskaya street 


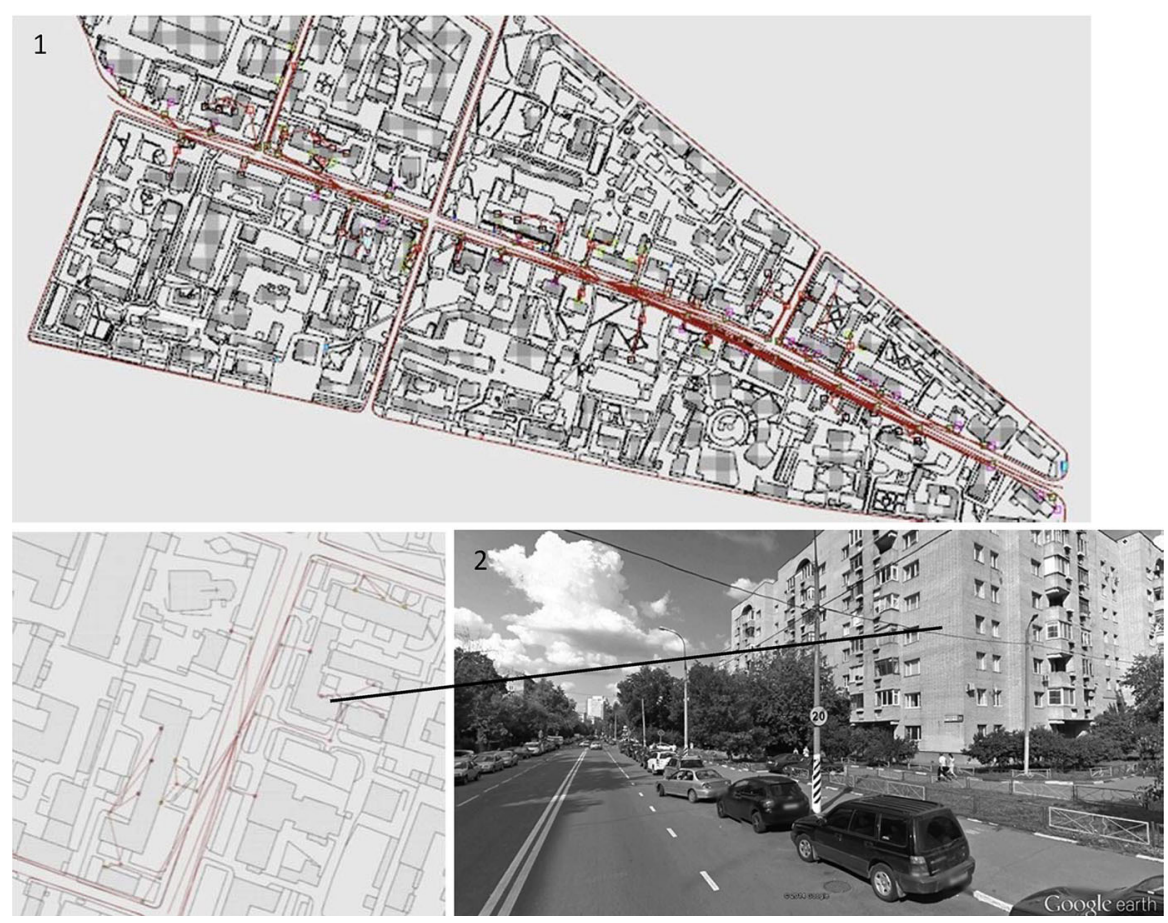

Fig. 11 Donskaya st 1 models and the generated graphs. The enormous size of the islands stresses the depth of entrances creating extremely secluded areas inside. Life is pushed inside the island towards privately owned areas. The more exposed facades are the ones able to capture some commercial activity. 2 Street view of one of the residential building typologies. This typology is analyzed earlier in the text according to the $Y-y-x-X$ principle
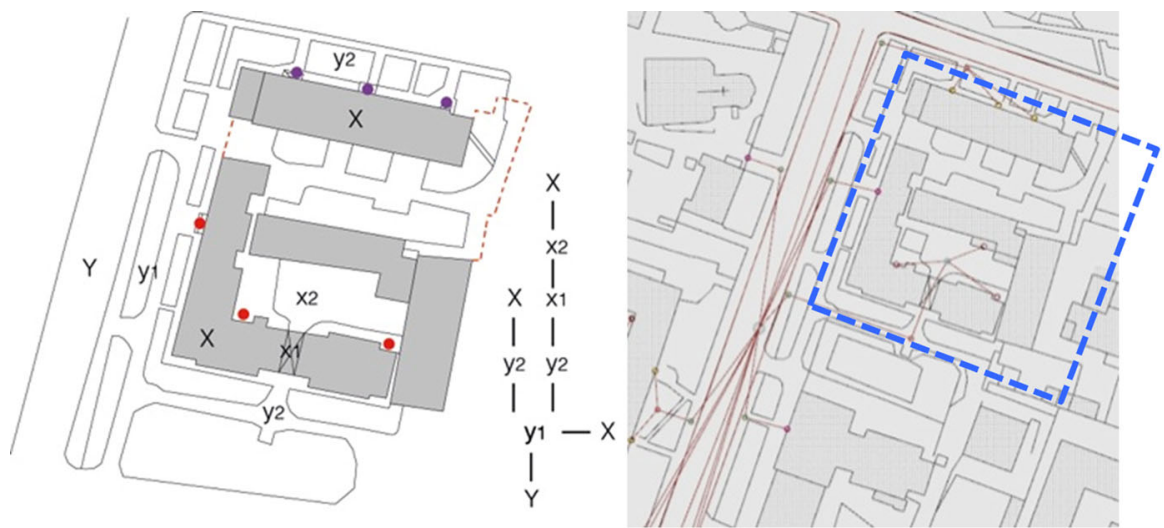

Fig. 12 Spatial arrangement public-private space at Donskaya street. Red points residential buildings' entrances, purple retail stores' entrances. Dashed line gates surrounding private space X (in this case accessed from another street therefore not part of analysis) 
during the day as well as at night. Multiple smaller streets and entrances that run directly into the streetscape, punctuate the length of the façade walls. The block length is rather short. The associated inner courtyards (x spaces) have smaller depth as compared to other case studies in Moscow. No gatedness is present.

The second case study_-Regendorfstrasse (Figs. 15, 16), is a typical living area with 2-4 storey buildings and smaller retail stores running along the street. Most of the housing can be accessed directly from the street. Though, there are situations where entrances are separated from the street either by elevated sidewalks or greenery, in very rare cases by fence.

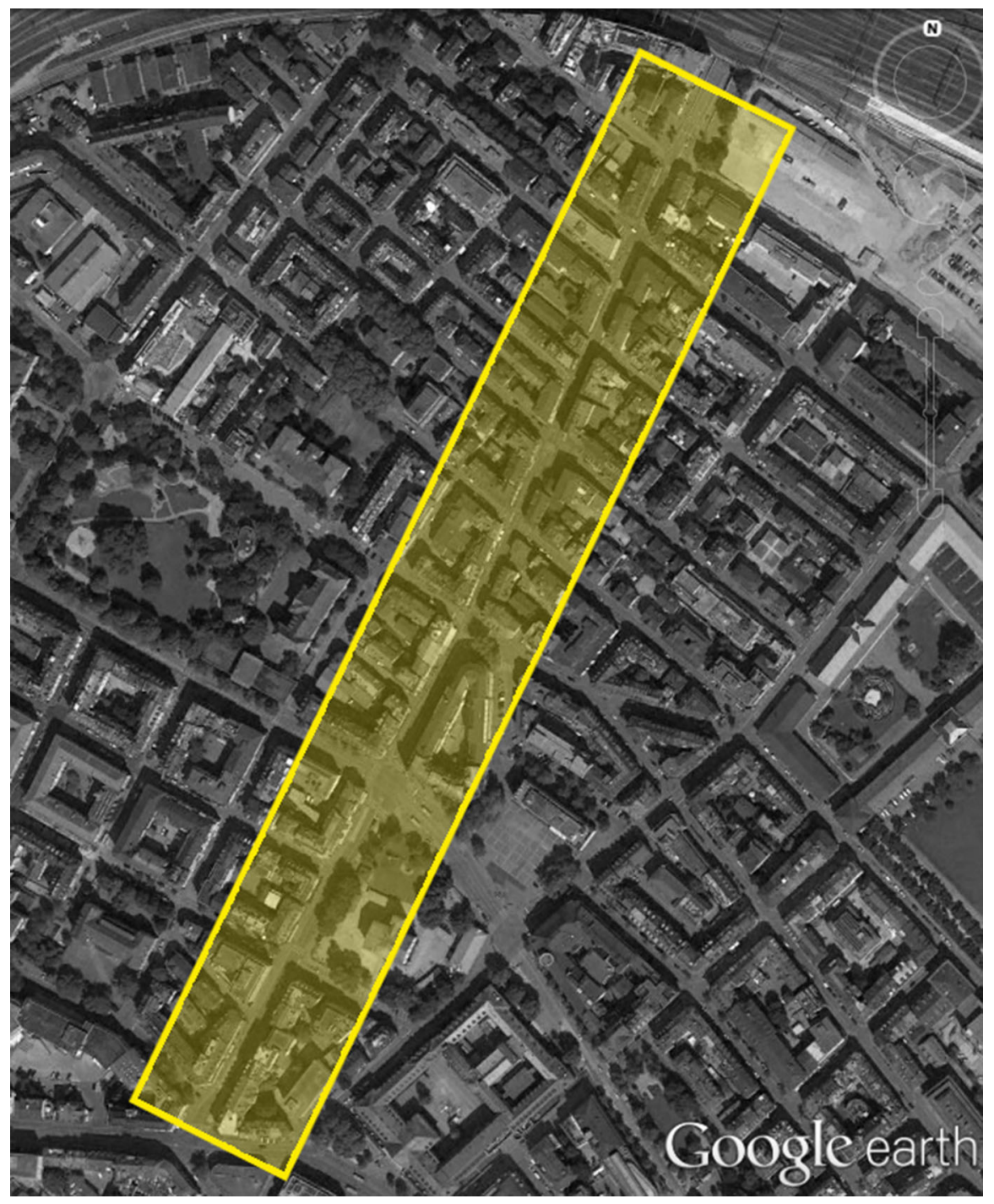

Fig. 13 Zurich case study I. Langstrasse 


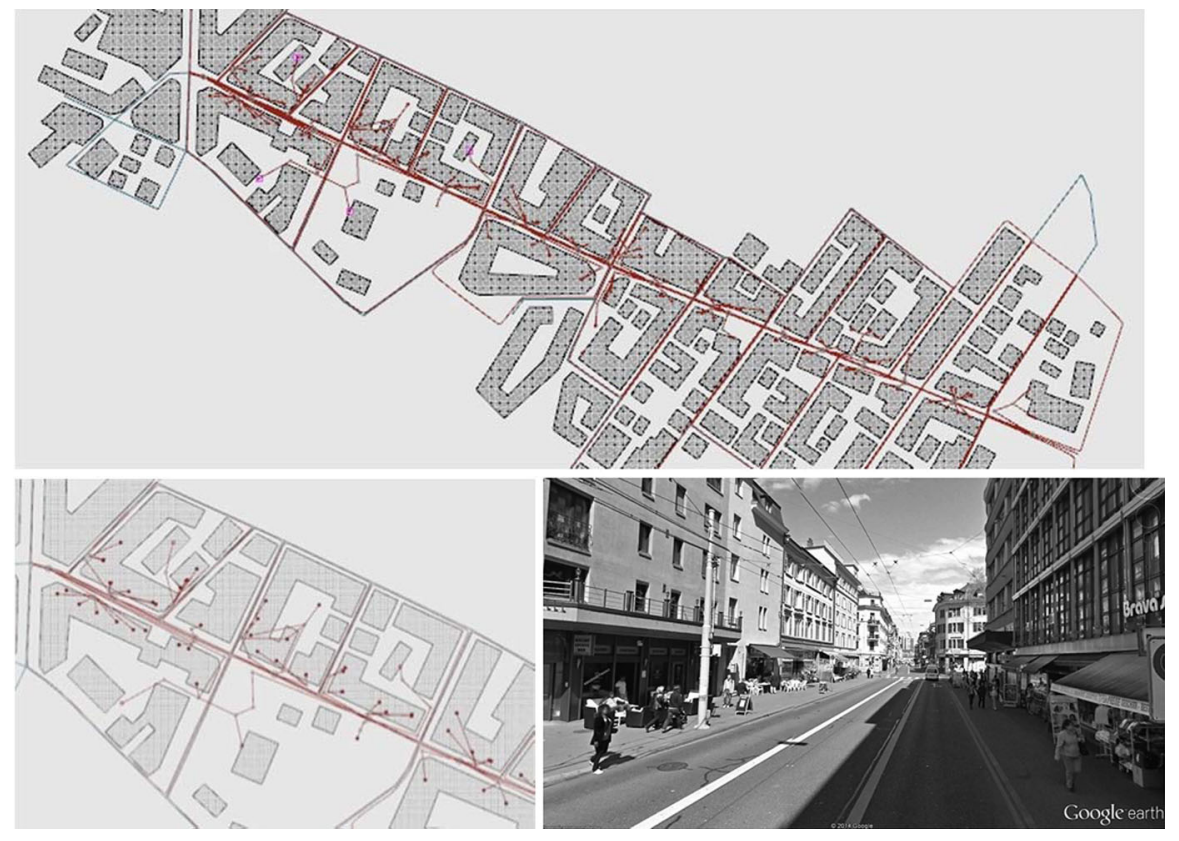

Fig. 14 Langstrasse: models and the generated graphs. General street view

In all the case studies the graphs were generated automatically using the same five design patterns as previously described. The calculations of the list of properties in Table 1 are also calculated using a common set of design patterns producing comparable measures for all streets. Tables 2, 3 and 4 show the values for properties

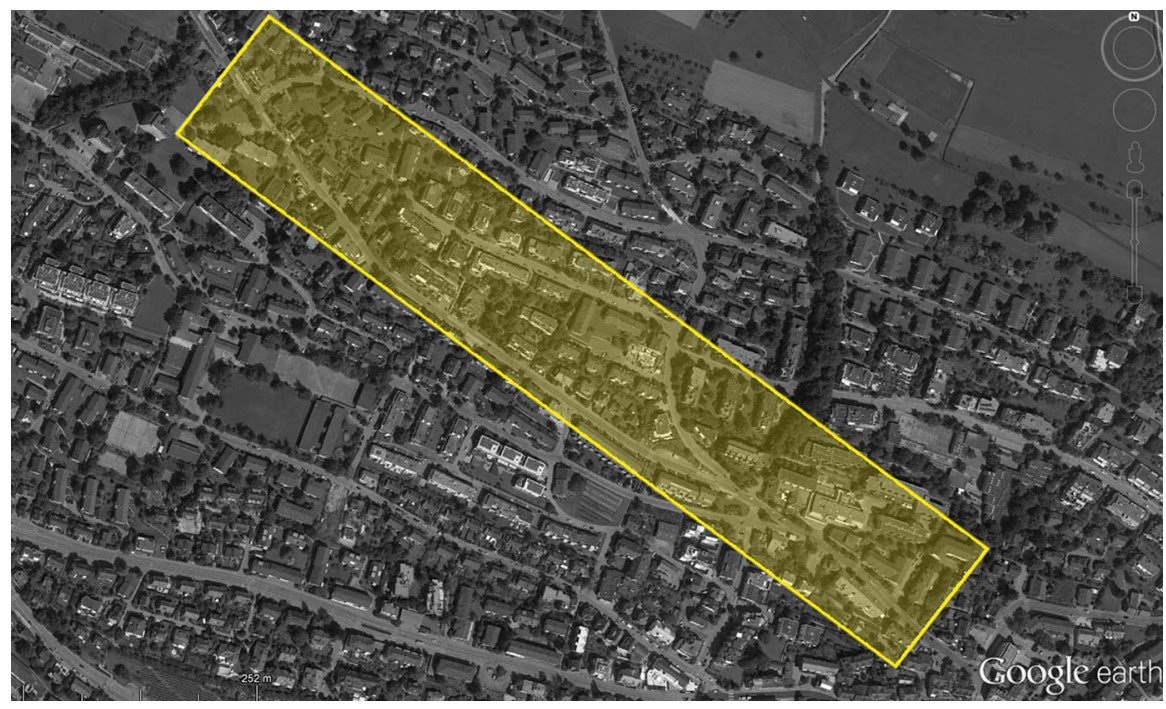

Fig. 15 Zurich case study II. Regendorfstrasse 


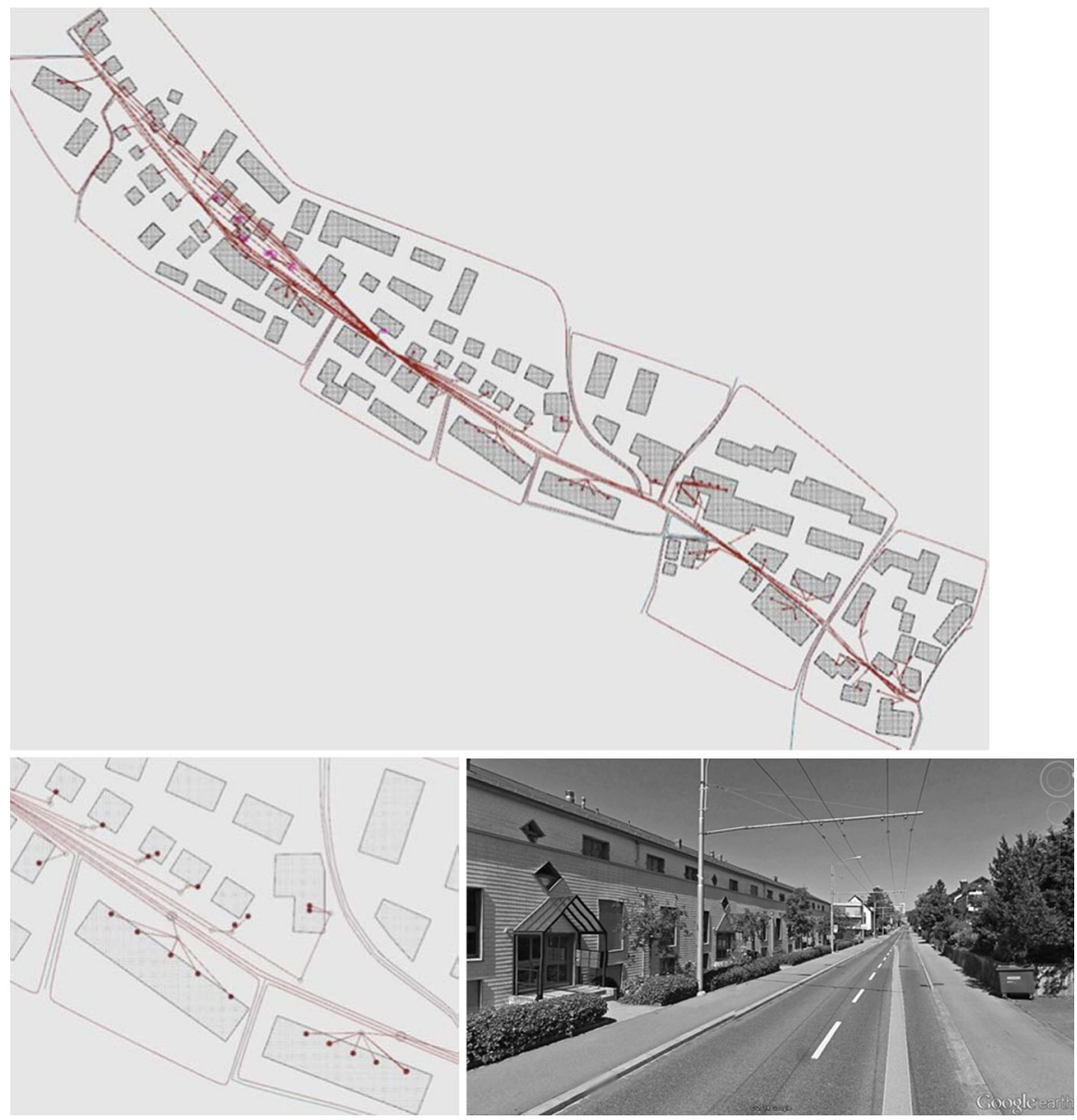

Fig. 16 Regendorfstrasse: models and the generated graphs. General street view

of Lisbon, Moscow and Zurich case studies respectively. The interpretation of these results will be done in Sect. 6 after explaining how we capture the measure of street liveliness.

\section{Street Permeability and Its Correlation to Liveliness}

A well balanced and lively street considering simply empirical observation will probably congregate mixed activities from dwelling to commercial activities including office spaces and services. The latter activities tend to prefer locations close to their potential public and therefore tend to be located in widely visible areas where the chances of pedestrians passing by are very high. The traditional space syntax measures of integration and choice give us an insight about the intensity of 
use of a street in a particular street network (Hillier 1996). Hillier calls it the urban buzz. Objectively, the measure of integration gives us a measure of the likelihood of someone wandering in a street network passing on a particular street. Hence, the term urban buzz. However, we want to capture how the morphology of the street space affects or not the street life in terms of a pedestrian viewpoint. This means that some street may have high integration (low RRA values) which may account for traffic use but have a totally different relation with pedestrian use, or even when still very active concerning pedestrian use (for which the term urban buzz still applies) yet may not be regarded as pleasant and therefore perceived as 'less livable' or less agreeable for the purpose of strolling.

In contemporary societies we can see that security and privacy are two issues that tend to push housing away from a direct contact with streets, a tendency that opposes the real security propensity of the street as observed by Jane Jacobs (1961) and later further supported by (Hillier 2004). If the research question would simply be to identify where the urban buzz is, the identification of best integration and best choice, or more intuitively, the identification of where the greatest concentration of opened activities is, would be enough to capture such information. However, we want to be able to capture liveliness (or potential liveliness) from the morphological characteristics of streets. There is a substantial difference: if we could identify the components of urban spatial structure that provide for liveliness or the potential of its occurrence in new designs, we should be able to objectively predict if our designs will become lively and pleasant, or not. This difference can be easily supported through the evidence that commercial spaces hidden from the main sidewalks due to complex spatial configurations seem to be commercially unattractive even though the street may be reasonably well connected and integrated in the network. Conversely, in segregated areas a space may also be commercially unattractive even when placed opening directly towards the sidewalk. It seems then that specific correlations between the two properties determine such attractiveness and henceforth contribute to the formation of liveliness.

The expression of the activity of people, the liveliness of a place or urban buzz seen as the swarming of people will be simply called liveliness. In this paper we suggest a method in which we correlate the empirically observed liveliness in the street with permeability $(P)$ measures. We believe that the intensity of life in a place is dependent on: (1) the intensity of transitions between $X$ cells and the street; and (2) on the visibility or exposure of the interfaces that allow such transitions, in other words, the exposure of entrances. We use the unifying term'permeability' for these characteristics of street space. We could then say that permeability should be a function of the density of entrances along the street and their mean depth, i.e., their exposure to the passerby. The density of entrances is given by the number of entrances $E$ divided by the street length $(S T L)$. By dividing by mean depth, the simple relation $P=(E / S T L) / M D$ is able to capture, at least in its essence, the measure we are looking for. Therefore, we propose for the measure of permeability the following equation:

$$
P=(E / S T L) / M D
$$


Table 1 Table of properties for street A

Properties for street A and their descriptions

Property Description

Total number of entrances

Total number of connections or $\# C$ links in the graph

Total number of nodes in the graph

Number of links with the carrier

Entrance depth

Total depth

Mean depth

Maximum depth

Number of street segments

Number of street sections

Street length

Average segment length

Number of entrances of depth 1 or number of entrances facing the street
\#E Total number of entrances in buildings of street $\mathrm{A}(X$ and $x$ ). $X$ space entrances refer to entrances in private cells (e.g., single family houses); $x$ space entrances refer to entrances in collective buildings containing private cells $X$ accessible from deeper spaces in $x$

$\# C \quad$ Expresses the overall connectivity of the model

$\# N \quad$ Indicates the total number of spaces in the system

\#Y Number of other streets connecting street A. Note that a junction may connect more than one street

$D \quad$ Measures the number of steps away from the carrier $Y$ that an entrance is considering the carrier to be the spaces giving access to street A

$T D$ Sums up the depth of all entrances in the street.

$$
T D=\sum_{i=1}^{n} d_{i}
$$

$M D \quad$ Gives the average depth of entrances in relation to street A. Expresses the extent to which we can say that entrances assume a reserved (or private) position from the street core.

$M D=\frac{T D}{\# C-1}$

$\max$ Depth of the deepest entrance. Expresses how reserved is the $d$ deepest entrance in the street

$\# S_{g} \quad$ Number of other streets including cul-de-sacs connecting street A less one (for traversable streets). Number of other streets including cul-de-sacs connecting to each side of the street A less two (for dual streets)

$\# S_{c} \quad$ Number of other streets excluding cul-de-sacs connecting street A less one (for traversable streets). Number of other streets excluding cul-de-sacs connecting to each side of the street A less two (for dual streets)

STL For traversable streets: sum of all segments length.

For dual streets: sum of all segments length divided by two. Street length is expressed in meters

$A S_{g} \quad A S_{g}=S T L / \# S_{g}$

Expresses how much a pedestrian should walk to find the next street junction

$\# E_{1} \quad$ Total number of entrances in buildings of street A facing directly the sidewalk or street core 
Table 1 continued

Properties for street A and their descriptions

\begin{tabular}{|c|c|c|}
\hline Property & & Description \\
\hline Direct permeability factor & $D P F$ & $\begin{array}{l}D P F=\left(\# E_{1}+\# N_{1}\right) / \# E \\
\text { where } \# E_{1} \text { and } \# N_{1} \text { represent respectively the number of } \\
\text { entrances of depth } 1 \text { and the number of nodes of depth } 1 . \\
\text { Expresses how much buildings in street A open directly } \\
\text { towards the sidewalk. The value } 1 \text { means that all buildings } \\
\text { open directly to the street. Low values correspond to streets } \\
\text { with reserved entrances but does not account for the depth of } \\
\text { street entrances }\end{array}$ \\
\hline Number of islands & $\# I$ & Number of islands facing street A \\
\hline Average island area & $A I A$ & $\begin{array}{l}\text { Gives an impression on the size of islands facing a street. In } \\
\text { other words, this is a sample of the 'grain of the grid' }\end{array}$ \\
\hline Island blocking factor & $I B F$ & $\begin{array}{l}I B F=1 /\left(A I A \times 10^{-4}\right) \\
\text { Expresses how much an island blocks access from the street to } \\
\text { the city. } 10,000 \text { is the area of an urban block with } \\
100 \times 100 \mathrm{~m} \text {. Considering Jane Jacobs claim that urban } \\
\text { blocks wider than } 100 \mathrm{~m} \text { tend to create barriers for } \\
\text { pedestrians, this factor indicates how much islands have more } \\
\text { or less blocking effect than the theoretical } 100 \times 100 \mathrm{~m} \\
\text { block. The value } 1 \text { corresponds to a blocking factor equal to } \\
\text { the one of a grid composed only by } 100 \times 100 \mathrm{~m} \text { blocks }\end{array}$ \\
\hline $\begin{array}{l}\text { Average number of entrances } \\
\text { per } 100 \mathrm{~m}\end{array}$ & $A E$ & $\begin{array}{l}A E=(\# E / S T L) \times 100 \\
\text { Expresses the density of entrances along a } 100 \mathrm{~m} \text { of street }\end{array}$ \\
\hline $\begin{array}{l}\text { Average distance between } \\
\text { entrances }\end{array}$ & $A D E$ & $\begin{array}{l}A D E=S T L / \# E \\
\text { This is the inverse property of } \mathrm{AE}\end{array}$ \\
\hline Typical block size & $T B S$ & $\begin{array}{l}\text { The typical block size takes the average island area }(A I A) \text { and } \\
\text { the average segment length }\left(A S_{g}\right) \text { and calculates the other } \\
\text { block side length }\left(B_{l}\right) \text { by dividing } A I A \text { per } A S_{g} \text {. The typical } \\
\text { block size is therefore given by } A S_{g} \times B_{l} \text {, where } A S_{g} \text { is the } \\
\text { side of the block facing street } \mathrm{A}\end{array}$ \\
\hline
\end{tabular}

This expression integrates the effect of depth within a certain entrance density along a street correlating the high exposure of many entrances with livelier activity. Higher values indicate livelier streets while lower values indicate more secluded streets. The fact that an area is livelier does not affirm that such area is better for dwelling. Residence may require more secluded areas; quietness may be an important requirement for such purpose. The following section shows the measured street properties stressing the latter remark and the next section discusses the results and their meaning.

\section{Street Models and Properties}

Tables 2, 3 and 4 show the street properties for Lisbon, Moscow and Zurich case studies respectively providing a set of comparative table of the measurements taken 


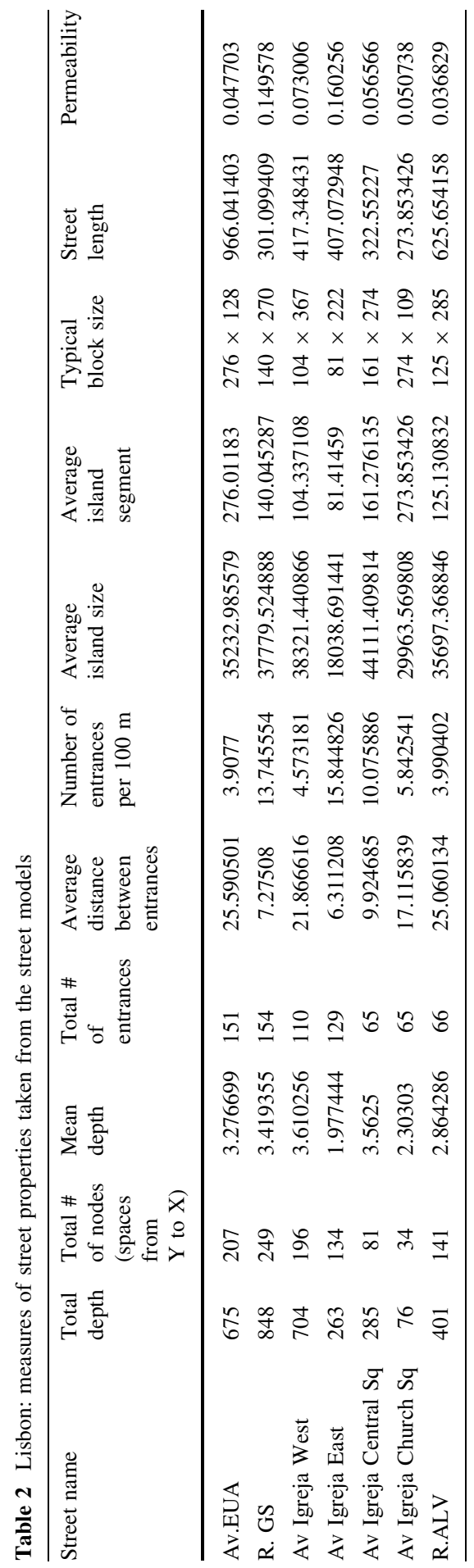




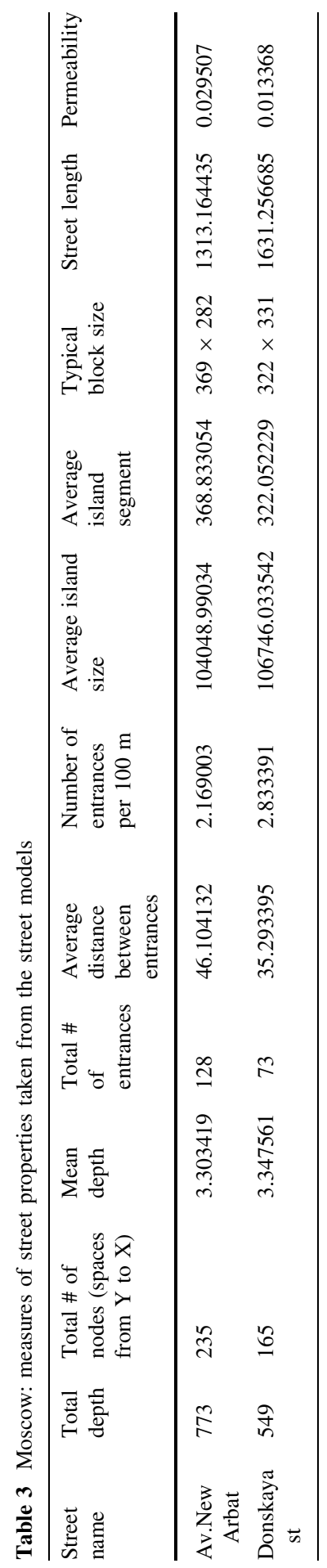




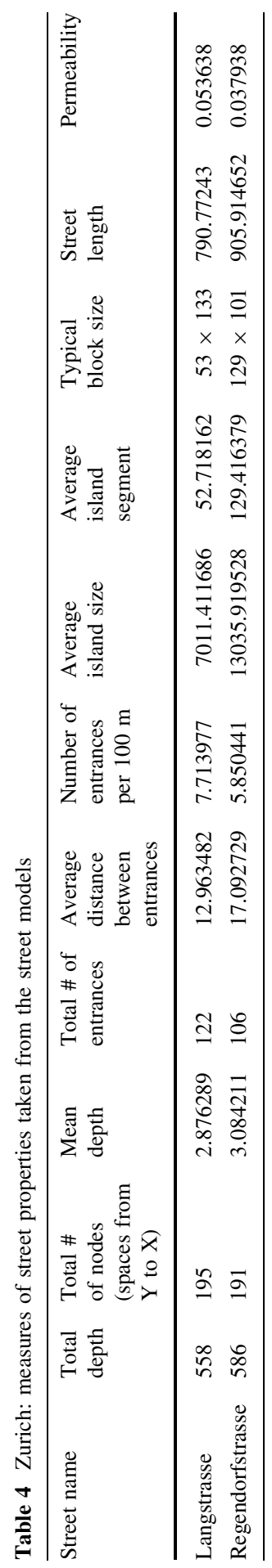


from the analytical models. Tables show some of the properties referred in Table 1 including the value for permeability provided by Eq. (1).

Despite the uniform criteria followed in choosing the case studies some differences immediately become evident between the Moscow case studies and the others. Moscow streets clearly belong to a different urban scale. This is evident in the values for average island size, average island segment and typical block size which, for the Moscow case, fall absolutely within the values that Jane Jacobs considers too high for containing typical neighborhood commercial activities and intense life.

Curiously, the value of mean depth does not necessarily correlate with the measures of permeability except for the case of Av da Igreja East where low depth corresponds to high permeability as would be expected if entrance exposure would be the single factor to consider.

Although the measures obviously identify the livelier areas in each town, a cross comparison of the values of permeability among the case studies might lead us to think that the Moscow areas are not lively at all even though the simple empirical observation of Lisbon streets may show a higher intensity in terms of urban buzz. This value is therefore significantly changed by the scale of the place. This should be a topic for further discussion. One thing is clear through all case studies: the denser the number of entrances the higher the liveliness value is. Mean depth only changes significantly this measure when its value is significantly different.

\section{Discussion}

In this study we propose one possible approach to objectively measure the relation between the street life and street configuration. In particular we look into the way streets and private spaces connect and how does this influence the activity in urban space. We chose several case studies based on our empirical experience. For consistency, for each case we selected two types of scenarios: (1) streets with prevailing public functions and; (2) streets with mostly residential functions. Obviously, streets with majority of public functions generate higher activity or, as we call it, street "liveliness" when compared to residential streets. Hence, our question was: how could we correlate the liveliness to physical spatial structure? The methodology presented in the paper is one possible way of objectively measuring permeability as an urban quality that influences liveliness. We used the number of entrances, mean depth of private spaces and, based on the principle that the density of entrances and their exposure to the public space are the most determinant factors in the generation of life, we correlated these to the length of the analyzed street. This relation is expressed by the Eq. (1). At first, we classified the case studies according to the level of their liveliness based on our empirical knowledge. In the next step we applied our method with the goal to measure the permeability. We ordered the street by perceived liveliness and our measures of permeability resulted in the same order. The streets with more intense activity received higher values (of permeability) while residential streets received the lower. The results were quite close to our preliminary (empirical) classification which 
Table 5 Syntactic values of mean depth, RRA, global (Rn) and local integration (R3) for the Lisbon streets (taken from DepthMap)

\begin{tabular}{lllll}
\hline Street name & Mean depth & RRA & Rn & R3 \\
\hline Av.EUA & 11.8984 & 1.0164 & 0.983865 & 3.59381 \\
R. GS & 12.6704 & 1.1128 & 0.918782 & 2.69225 \\
Av Igreja & 12.1579 & 1.0406 & 0.960983 & 3.45997 \\
R.ALV & 12.9321 & 1.0884 & 0.881962 & 2.69720 \\
\hline
\end{tabular}

gives us the reason to state that this methodology could be used as a way of predicting the "liveliness" of urban space.

However, further fine-tuning of the method and collected data is important. One such example is the interpretation of the way the permeability factor or island blocking factor influence the behavior of urban space. Considering Jane Jacobs remarks on the size of urban blocks we should further explore the meaning of the island blocking factor and correlate this information with the scale of the place.

Another question is how to distinguish between the types of entrances (public or private). In particular, from the topological viewpoint, we should distinguish two types of entrances: (1) those giving access directly to an $X$ cell which may be shops or a single family house; from (2) those giving access to other distribution spaces ( $x$ internal private space) distributing access to more secluded $X$ cells. The simplest cases will be the typical left-right apartment building types, typically showing building entrance hall $\left(x_{1}\right) \rightarrow$ staircase/elevator $\left(x_{2}\right) \rightarrow$ and entrance hall to apartments $\left(x_{3}\right)$. More complex cases show for instance: building entrance hall $\left(x_{1}\right) \rightarrow$ staircase/elevator $\left(x_{2}\right) \rightarrow$ hall $\left(x_{3}\right) \rightarrow$ gallery $\left(x_{4}\right) \rightarrow$ and entrance to apartments $\left(x_{5}\right)$. By adding the value of territorial depth inside buildings to the analytical models we can perhaps fine tune the analysis and be able to capture a finer grain of the picture. This may easily explain the difference between the two sides of the street in the case of R.GS and the difference between the west and the east parts of Av da Igreja.

One thing we can say for the proposed method is that it easily captures the difference along the four distinct parts of Av da Igreja, something that would not happen with the traditional space syntax approach. Their properties are so distinct that it is even possible to recapture the main morphological characteristics of the different parts from the correlations of the measurements. In the end, the measures distinctly comply with the impressions obtained through direct observation.

It is easy to accept, however, that the position of the street in the network influences its potential life. The correlation with the syntactic measures of global $(R n)$ and local integration $(R 3)$ could be able to fine tune a global and local measure for liveliness. Looking at the syntactic measures for the Lisbon case (Table 5) we can easily understand that these would stress the distinction between Av da Igreja and R.GS which are the livelier spaces by highlighting how Av da Igreja has not just a privileged morphology for generating liveliness (especially on the east part) but also a privileged position in the network being a main artery in the Alvalade neighborhood. However, space syntax measures do not show much distinction 
between Av.EUA and Av da Igreja or between R.GS and R.ALV, which, as we have seen are quite different in their properties. Our proposed method clearly captures this difference.

The trickier aspect of the methodology is scale, as already mentioned at the end of the previous section-the scale of the "city grain" matters. This is probably easier to understand when we think the larger scale of Moscow streets is somehow influencing some of the measures. For instance, street width is not being taken into account in our measures and as referred by Oliveira the ratio of building height and street width is a meaningful factor. We did not consider it purposely due to critiques stating that this proportion may be maintained at different scales but producing very different street character (Moughtin 2003). However, we would like to claim that the two dimensions separately matter rather than the proportion between the two. Calculations expressing the scale of the grid will therefore need further investigation and may lead us towards a refined measure for liveliness (if a unique value is really more important than comparing a set of simpler and more intuitive ones).

Finally, we should differentiate the property of livability from liveliness. Liveliness is a property derived from the activity of people in a place while livability stresses more the pleasantness of the place for living. Therefore, a very lively place may not be perceived quiet enough for living and a very quiet area, not very lively, may be seen as very pleasant and hence very livable.

\section{Future Work}

Obviously, there exist many other influencing factors that we do not yet consider in our method and that stimulate the activity in the street. Those are the level of integration of the street within the local/global network, prevailing functions (commerce, entertainment, leisure or residence) and others. Therefore, we plan to develop further our methodology with the goal to add additional information such as, for example, the values of integration in the network and correlate the street location in the network, its liveliness and morphological features. A particularly interesting development would be to gather enough case studies as well as finer detailed measurements that would allow producing an accurate correlation of such measurements with specific street types. If the set of case studies is wide enough, not only the correlation could show interesting results but we may also be able to identify what influences the character of specific street types and what can be expected from particular designs.

Extensive applications of this method for (1) improving and testing the method, (2) searching for new correlations between properties and (3) for street categorization, are our next goals.

Acknowledgments Beirão would like to thank Nuno Montenegro for his initial input and Francisco Serdoura for providing the syntactic measures for Lisbon. I am also sincerely grateful to Anastasia Koltsova for her industrious effort in putting forward this work with me and bringing the Moscow and Zurich case studies in. Many thanks to Francisco Serdoura, Jorge Gil, Ljiljana Ćavić and Robert Woodbury for the readings and comments. 


\section{References}

Barton, Hugh, Marcus Grant, and Richard Guise. 2003. Shaping Neighbourhoods: A Guide for Health, Sustainability and Vitality. London: Spon Press.

Batty, Michael. 2004. A New Theory of Space Syntax. Center for Advanced Spatial Analysis, Working Paper 75. http://www.bartlett.ucl.ac.uk/casa/pdf/paper75.pdf. Accessed 28 December 2014.

Berghauser Pont, Meta, and Per Haupt. 2010. Spacematrix. Space, Density and Urban Form. Rotterdam: NAi.

Habraken, John. 2000. The Structure of the Ordinary: Form and Control in the Built Environment. Jonathan Teicher, ed. Cambridge, MA: MIT Press.

Hillier, Bill. 1996. Space Is the Machine. http://eprints.ucl.ac.uk/3881/1/SITM.pdf. Accessed 28 December 2014.

Hillier, Bill. 2004. Can Streets Be Made Safe? Urban Design International 9 (1): 31-45.

Hillier, Bill, and Julienne Hanson. 1984. The Social Logic of Space. Cambridge: Cambridge University Press.

Jacobs, Jane. 1961. The Death and Life of Great American Cities. New York: Random House.

Moughtin, Cliff. 2003. Urban Design: Street and Square, 3rd ed. Oxford: Architectural Press.

Oliveira, Vitor. 2013. Morpho: a Methodology for Assessing Urban Form. Urban Morphology 17 (1): 21-23.

Ståhle, Alexander, Lars Marcus, and Anders Karlström. 2005. Place Syntax - Geographic Accessibility with Axial Lines in GIS. http://www.spacescape.se/pdf/Place\%20syntax\%20paper_Stahle_Marcus_ 2005.pdf. Accessed 28 December 2014.

José Nuno Beirão was awarded a professional degree in architecture from the Faculty of Architecture of the Technical University of Lisbon in 1989. He has practiced architecture and urban design since then started the architectural firm B Quadrado Arquitectos with Miguel S. Braz in 1998. Their work and portfolio is available at http://www.bquadrado.com. José Nuno Beirão concluded his PhD dissertation entitled 'CItyMaker: Designing Grammars for Urban Design' at the TU Delft Faculty of Architecture in 2012. He developed a method and a set of tools to generate alternative solutions for different urban contexts by combining design patterns encoding typical design moves used by urban designers. The patterns were developed from observation of typical urban design procedures, first encoded as discursive grammars and later translated into parametric design patterns. The set of tools generates alternative design and measures properties of those designs which can then be used for assessing the different options and to support design decision. The integrated set of tools, involving analytical, generative and assessment tools have been argued to constitute the basis of the concept of city information modeling whose acronym CIM can be read in CItyMaker. His research interests are involved in the development of customizable and flexible design systems, focused on housing since 1998 and more intensively on urban design since 2001. His current interests are focused on the development of shape grammars for urban design and on the use of the generative capabilities of shape grammars to support the urban design process and foster design exploration.

Anastasia Koltsova completed her studies in Architectural Association School of Architecture in London with MArch degree (DRL programme). Most of her coursework in Design Research Laboratory was dedicated to development of scripted urban systems and form design research under the direction of Patrik Schumacher. She is research assistant and $\mathrm{PhD}$ student at the Chair of Information Architecture at ETH, Zurich. Her thesis proposes using an inverse urban design method as a way to (1) measure certain pedestrian space quality indicators of existing pedestrian areas in Switzerland and Russia and (2) translate them into new designs. This research stretches between the two following research domains: urban design and computational sciences (parametric design in particular). 